\author{
Military Technical College \\ Kobry El-Kobbah, \\ Cairo, Egypt
}

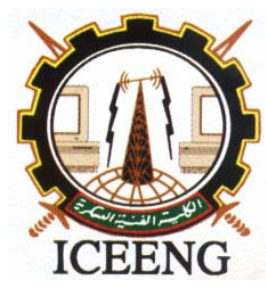

\title{
Modeling, Analysis and Control of Doubly Fed Induction Generators for Wind Turbines
}

Mahmoud M. Badreldien*, Usama R. Abouzayed*, Amged S. El-Wakeel*, Almoataz Y. Abdelaziz**

\section{$\underline{\text { Abstract }}$}

This paper presents modeling, analysis and control of a grid connected doubly fed induction generator (DFIG) wind turbine, during steady-state and transient operations. A mathematical model for different parts of the wind energy conversion system using DFIG has been examined using MATLAB/SIMULINK. A control structure using standard proportional integral (PI) controller and a voltage-oriented control strategy based on a rotating reference frame has been used.

The machine model considers operating conditions below and above synchronous speed. The Maximum Power Point Tracking (MPPT) method has been presented also to improve efficiency and energy extraction in wind turbine systems. Characteristic power curve method has been used as one of the popular MPPT methods.

In this paper, simulation results of the DFIG model have been presented. Then, DFIG model has been connected to the grid model and examined using PI controller under different conditions. The Internal Model Control (IMC) method has been used for tuning the PI controller. The proposed PI controller shows stable operation at different conditions.

Keywords-Doubly fed induction generator (DFIG), maximum power point tracking (MPPT) method, vector control, wind energy conversion system (WECS), Rotor side converter (RSC), Grid side converter (GSC).

* Egyptian Armed Forces

** Ain Shams University 


\section{1-Introduction}

The use of renewable sources for electric power generation has experienced a huge interest since the past decade. Worldwide concern about the environmental pollution and a possible energy crisis has driven researchers to discover newer, clean and better means of generating electrical energy. In this race, Wind Energy Conversion Systems (WECS) have stood ahead of other renewable energy sources like solar energy, which still lags behind owing to high cost per kilowatt-hour (kWh) of electrical power generated. Overall, the contribution of these renewable energy sources to the power system has been increased rapidly from the last two decades.

Wind turbines are designed to produce electrical energy as possible and therefore they are generally designed to yield maximum output at wind speeds around $13 \mathrm{~m} / \mathrm{s}$. On the case of stronger wind, it is necessary to waste a part of the excess energy of the wind in order to avoid damaging the wind turbine. All wind turbines are therefore designed with some sort of power control[1]. The control of the power extracted from the wind can be done in several ways. Stall and pitch control (or a combination) seem to be the prevalent methods in modern wind turbines[2].

Among all the available technologies for WECS, DFIG is the most accepted because it combines the advantages of reduced converter ratings for power conversion and an efficient power capture due to the variable speed operation.

In the DFIG concept, the induction generator is grid-connected at the stator terminals, but the rotor terminals are connected to the grid via a partial-load Variable Frequency AC/DC/AC Converter (VFC).

With the advanced power electronic techniques, a back-to-back converter, which consists of two bidirectional converters and a dc link, acts as an optimal operation tracking interface between generator and grid[3-5]. Voltage Oriented Control (VOC) is applied to both Rotor Side Converter (RSC) and Grid Side Converters (GSC) to achieve desirable control on voltage and power[6-8]. Generally, VOC has been presented based on DFIG mathematical equations. However, a three-phase filter is commonly used to couple the grid-side converter into the grid.

It is possible to control rotor current injection using a controlled converters to ensure effective operation in both sub-synchronous and super-synchronous speed modes[6]. Decoupled control of active and reactive powers using the vector control has been discussed in detail by researchers[9, 10]. In a DFIG, both the stator and the rotor are able to supply active power. The direction of power flow through the rotor circuit is dependent on the wind speed and accordingly the generator speed. Below the synchronous speed, active power flows from the grid to the rotor side and RSC acts as the voltage source inverter while the GSC acts as a rectifier. Above the synchronous speed, RSC acts as the rectifier, and GSC acts as the inverter. The converter handles only around $25 \%$ of the machine rated power while the range of the speed variation is $30 \%$ around the synchronous speed [11].

This paper is organized as follows. The wind power, wind turbine and DFIG Models have been introduced in Section 2. Section 3 presents the control system design, design of RSC 
and design of GSC controllers. Section 4 presents the simulation results which are followed by the conclusion in Section 5 .

\section{2-Wind Power, Wind Turbine and DFIG Models}

The basic configuration of variable speed WECS schematic is shown in Figure (1). The Wind Turbine (WT) is connected to the induction generator through a mechanical shaft system, which consists of a low-speed shaft, connected to wind turbine, and a high-speed shaft, connected to DFIG, and a gearbox in between.

The wind turbine catches the wind through its rotor blades and transfers it to the rotor hub. The rotor hub is attached to a low speed shaft, connected to a gear box. The high speed shaft drives an electric generator which converts the mechanical energy to electric energy and delivers it to the grid. As the wind speed varies, the power captured, converted and transmitted to the grid also varies.

\section{2-1 Wind Power and Wind Turbine Models}

The mechanical power delivered to the shaft is a function of wind speed, blade pitch angle and shaft speed. The function of the wind power module is to compute the wind turbine mechanical power (shaft power) from the energy contained in the wind, using the following formula[12, 13]:

$\mathrm{P}_{\mathrm{m}}=\frac{1}{2} \rho \mathrm{A}_{\mathrm{r}} \mathrm{v}_{\mathrm{w}}^{3} \mathrm{C}_{\mathrm{p}}(\beta, \lambda)$

A relation between $\mathrm{Cp}$ versus $\lambda$ at different blade pitch angles is shown in Figure (2).

$C_{p}(\beta, \lambda)=\sum_{i=0}^{4} \sum_{j=0}^{4} \alpha_{i j} \beta^{i} \lambda^{j}$

$\lambda=\frac{\mathrm{r} \omega_{\mathrm{w}}}{\mathrm{v}_{\mathrm{w}}}$

Where $\alpha_{i j}$ is $C_{p}$ coefficient and its values are given in [14].

Generally, there is a unique wind turbine rotational speed to achieve the maximum power coefficient, $C_{P-\max }$, and thereby the maximum mechanical power. If the wind speed is below the rated value, the wind turbine operates in the variable speed mode. Hence the generator rotational speed is adjusted by DFIG speed control such that $C_{P}$ remains at the $\mathrm{C}_{\mathrm{P}-\max }$ point.

In this operating mode, the wind turbine pitch control is deactivated and the pitch angle $\beta$ is fixed at minimum. However, if the wind speed increases above the rated value, the pitch control is activated to increase the wind turbine pitch angle to reduce the mechanical power extracted from the wind. 


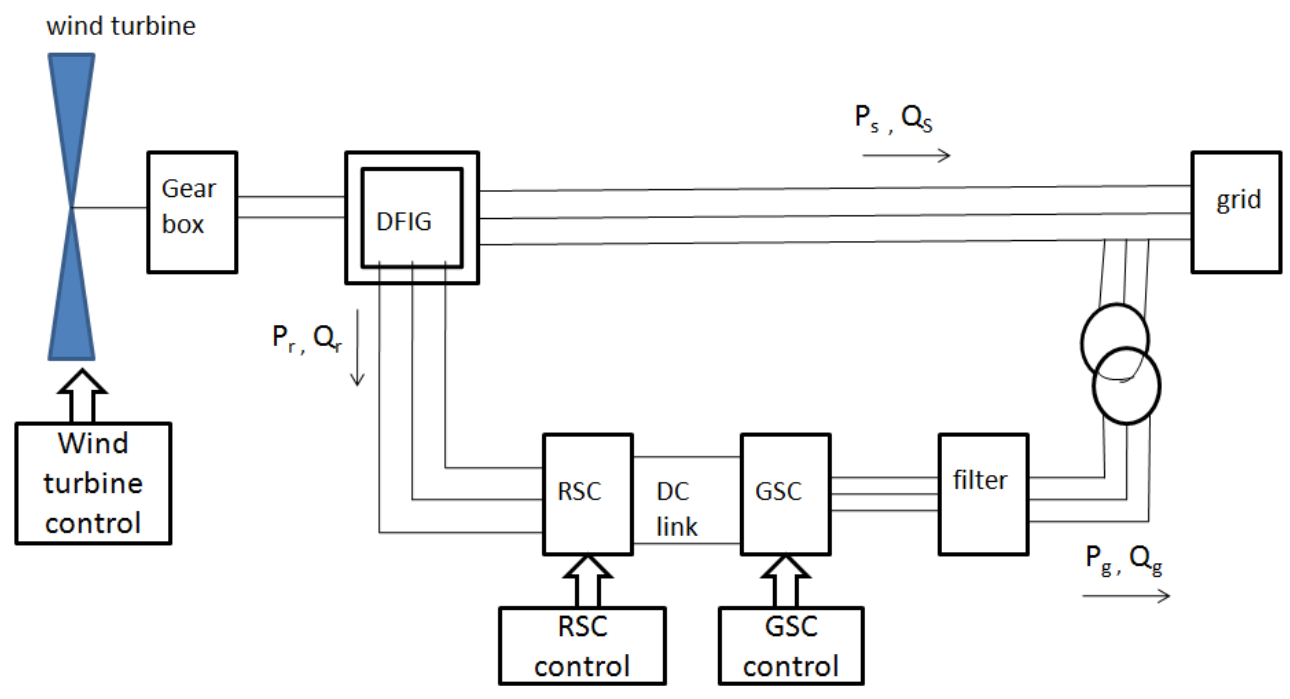

Figure (1) wind turbine DFIG system configuration

The power captured by a DFIG is defined under four different conditions as shown in Figure (3) . Initially, before the cut-in wind speed, the power output of the generator is zero as the required driving torque is not available. After crossing the cut-in speed, the turbine operates in the speed control mode and the DFIG is controlled for maximum energy extraction. Above rated wind speed, the turbine operates in the power control mode where the output power generated by the machine is kept under control by regulating the pitch angles of the blades. Beyond cut-out wind speed, the turbine is shut down and no output power is generated. Thus, the overall performance of the DFIG depends not only on the wind but also on the integrated generator and aerodynamic control systems which should effectively co-ordinate under variable wind conditions.

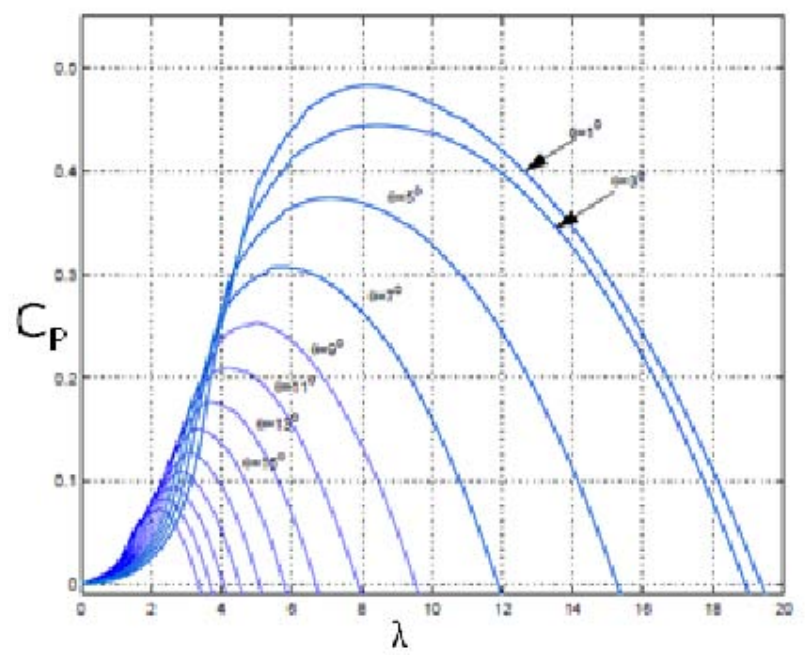

Figure (2) Wind turbine Cp curves

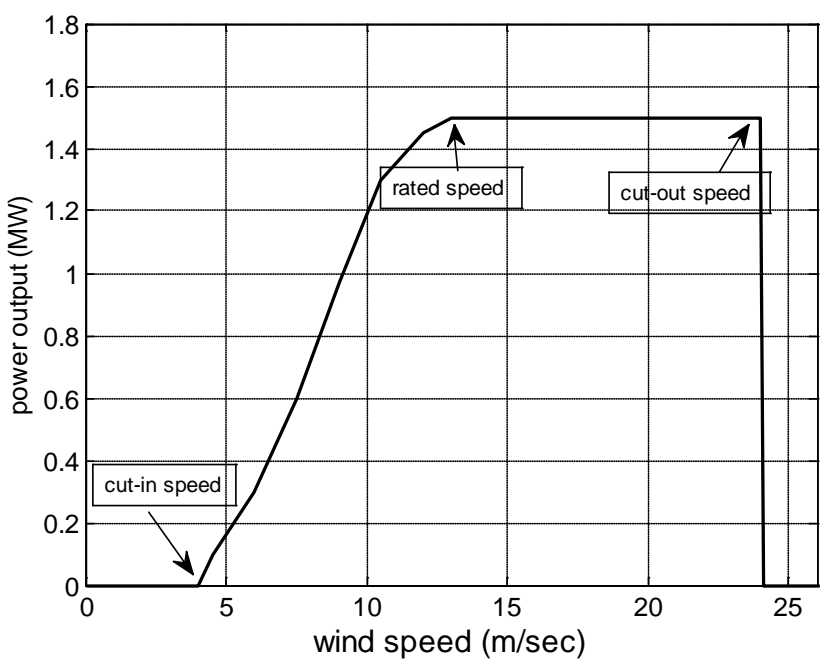

Figure (3) DFIG operation under different wind speeds 


\section{2-2 Modeling of DFIG}

The DFIG is used to produce electrical power at constant frequency whatever wind and shaft speed conditions. The classical d-q Park reference frame has been used [6, 15, 16]. The reorganized DFIG model based on synchronously rotating reference frame has been presented by the following equations[4]:

$$
\begin{aligned}
& \left\{\begin{array}{l}
V_{d s}=R_{s} I_{d s}+\dot{\varphi}_{d s}-\omega_{s} \varphi_{q s} \\
V_{q s}=R_{s} I_{q s}+\dot{\varphi}_{q s}+\omega_{s} \varphi_{d s}
\end{array}\right. \\
& \left\{\begin{array}{l}
V_{d r}=R_{r} I_{d r}+\dot{\varphi}_{d r}-\omega_{r} \varphi_{q r} \\
V_{q r}=R_{r} I_{q r}+\dot{\varphi}_{q r}+\omega_{r} \varphi_{d r}
\end{array}\right. \\
& \left\{\begin{array}{l}
\varphi_{d s}=L_{s} I_{d s}+L_{m} I_{d r} \\
\varphi_{q s}=L_{s} I_{q s}+L_{m} I_{q r}
\end{array}\right. \\
& \left\{\begin{array}{l}
\varphi_{d r}=L_{r} I_{d r}+L_{m} I_{d s} \\
\varphi_{q r}=L_{r} I_{q r}+L_{m} I_{q s}
\end{array}\right.
\end{aligned}
$$

The generator output power frequency should be equal to grid frequency, so the frequency of the rotor current should satisfy the slip frequency constrain, $\omega_{\mathrm{r}}=\omega_{\mathrm{s}}-\omega_{\mathrm{m}}$. The per-unit electromagnetic torque equation is given by[4, 7]:

$\mathrm{T}_{\mathrm{e}}=\varphi_{\mathrm{ds}} \mathrm{I}_{\mathrm{qs}}-\varphi_{\mathrm{qs}} \mathrm{I}_{\mathrm{ds}}=\varphi_{\mathrm{qr}} \mathrm{I}_{\mathrm{dr}}-\varphi_{\mathrm{dr}} \mathrm{I}_{\mathrm{qr}}=\mathrm{L}_{\mathrm{m}}\left(\mathrm{I}_{\mathrm{qs}} \mathrm{I}_{\mathrm{dr}}-\mathrm{I}_{\mathrm{ds}} \mathrm{I}_{\mathrm{qr}}\right)$

Neglecting the power losses associated with the stator and rotor resistances, the active and reactive stator powers are:

$$
\begin{aligned}
& P_{s}=(3 / 2)\left(V_{d s} I_{d s}+V_{q s} I_{q s}\right) \\
& Q_{s}=(3 / 2)\left(V_{q s} I_{d s}-V_{d s} I_{q s}\right),
\end{aligned}
$$

And the active and reactive rotor powers are given by

$P_{r}=(3 / 2)\left(V_{d r} I_{d r}+V_{q r} I_{q r}\right)$

$Q_{r}=(3 / 2)\left(V_{q r} I_{d r}-V_{d r} I_{q r}\right)$

The MATLAB/SIMULINK software library provides the standard model of the DFIG, which is used in this paper.

\section{3-Design of Control Systems}

The control system consists of both RSC and GSC controllers. RSC control provides a control of stator active and reactive power independently. GSC controller keeps DC link voltage constant regardless of the magnitude and direction of the rotor power. It can also control the reactive power exchanged between the grid and GSC and so on power factor. 
The wind turbine controller controls the pitch angle of the blades, which determines the mechanical power that the turbine extracts from the wind.

\section{3-1 Design of RSC Controller}

The RSC control scheme consists of two control loops, the inner current control loop and outer control loop. The inner loop regulates the d-axis and q-axis rotor current components, $\mathrm{I}_{\mathrm{dr}}$ and $\mathrm{I}_{\mathrm{qr}}$. The outer control loops regulate both the stator active and reactive power independently.

In the stator-voltage oriented frame, the d-axis of the reference frame is aligned along the stator-voltage space vector and the grid voltage applied to the stator is assumed constant, then the stator q-axis voltage would be zero and the d-axis voltage would be constant i.e. $\mathrm{V}_{\mathrm{ds}}=\mathrm{V}_{\mathrm{s}}, \mathrm{V}_{\mathrm{qs}}=0$ and $\varphi_{\mathrm{qs}}=\varphi_{\mathrm{s}}, \varphi_{\mathrm{ds}}=0$. Substituting in equations 6,9,10 gives:

$$
\begin{aligned}
& \mathrm{P}_{\mathrm{s}}=(3 / 2)\left(\mathrm{V}_{\mathrm{ds}} \mathrm{I}_{\mathrm{ds}}\right) \\
& \mathrm{Q}_{\mathrm{s}}=-(3 / 2)\left(\mathrm{V}_{\mathrm{ds}} \mathrm{I}_{\mathrm{qs}}\right) \\
& \mathrm{I}_{\mathrm{ds}}=-\frac{\mathrm{L}_{\mathrm{m}}}{\mathrm{L}_{\mathrm{s}}} \mathrm{I}_{\mathrm{dr}} \\
& \mathrm{I}_{\mathrm{qs}}=\frac{\mathrm{L}_{\mathrm{m}}}{\mathrm{L}_{\mathrm{s}}}\left(\mathrm{I}_{\mathrm{ms}}-\mathrm{I}_{\mathrm{qr}}\right) \\
& \mathrm{P}_{\mathrm{s}}=-(3 / 2)\left(\mathrm{V}_{\mathrm{ds}} \frac{\mathrm{L}_{\mathrm{m}}}{\mathrm{L}_{\mathrm{s}}} \mathrm{I}_{\mathrm{dr}}\right) \\
& \mathrm{Q}_{\mathrm{s}}=-(3 / 2) \mathrm{V}_{\mathrm{ds}} \frac{\mathrm{L}_{\mathrm{m}}}{\mathrm{L}_{\mathrm{s}}} \quad\left(\mathrm{I}_{\mathrm{ms}}-\mathrm{I}_{\mathrm{qr}}\right)
\end{aligned}
$$

It is clear from the last equations that $\mathrm{P}_{\mathrm{s}}$ and $\mathrm{Q}_{\mathrm{s}}$ can be controlled independently by regulating the rotor current components $\mathrm{I}_{\mathrm{dr}}$ and $\mathrm{I}_{\mathrm{qr}}$, respectively. Consequently, the reference values of $\mathrm{I}_{\mathrm{dr}}$ and $\mathrm{I}_{\mathrm{qr}}$ can be determined from the outer power control loops. the d,q-axes rotor voltage equations can be written as [10]:

$\begin{cases}V_{d r}=\left(R_{r}+\sigma p\right) I_{d r}-s \omega_{s}\left(L_{r} I_{q r}+L_{m} I_{q s}\right) & =V_{d r}^{1}+V_{d r}^{2} \\ V_{q r}=\left(R_{r}+\sigma p\right) I_{q r}+s \omega_{s}\left(L_{r} I_{d r}+L_{m} I_{d s}\right) & =V_{q r}^{1}+V_{q r}^{2}\end{cases}$

$V_{d r}^{1}, V_{q r}^{1}$ are called current regulation parts of $\mathrm{d}$ and q axes RSC voltages respectively and are simulated as shown in Figure (4). where $\sigma=\mathrm{L}_{\mathrm{r}}-\mathrm{L}_{\mathrm{m}}{ }^{2} / \mathrm{L}_{\mathrm{s}}$.
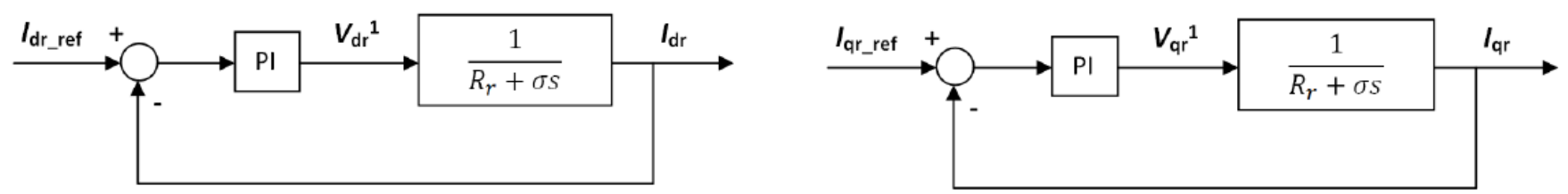

(a) Current regulation part of d-axis RSC voltage

(b) Current regulation part of q-axis RSC voltage Figure (4) Current regulation part of $d$ and $q$ axes RSC voltage 
It is possible to design the following control loops and PI controllers as following:

$$
\left\{\begin{array}{l}
\mathrm{V}_{\mathrm{dr}}^{1}=\left(\mathrm{K}_{\mathrm{pr}}+\frac{\mathrm{K}_{\mathrm{ir}}}{\mathrm{s}}\right)\left(\mathrm{I}_{\mathrm{dr}_{\text {rref. }}}-\mathrm{I}_{\mathrm{dr}}\right) \\
\mathrm{V}_{\mathrm{qr}}^{1}=\left(\mathrm{K}_{\mathrm{pr}}+\frac{\mathrm{K}_{\mathrm{ir}}}{\mathrm{s}}\right)\left(\mathrm{I}_{\mathrm{qr} \text { ref. }}-\mathrm{I}_{\mathrm{qr}}\right)
\end{array}\right.
$$

The flux equation can be stated as:

$$
\begin{aligned}
& \left\{\begin{array}{l}
\varphi_{\mathrm{ds}}=\left(\mathrm{V}_{\mathrm{qs}}-\mathrm{I}_{\mathrm{qs}} \mathrm{R}_{\mathrm{s}}\right) / \omega_{\mathrm{s}} \\
\varphi_{\mathrm{qs}}=\left(\mathrm{V}_{\mathrm{ds}}-\mathrm{I}_{\mathrm{ds}} \mathrm{R}_{\mathrm{s}}\right) /\left(-\omega_{\mathrm{s}}\right)
\end{array}\right. \\
& \varphi_{s}=\sqrt{\varphi_{d s}{ }^{2}+\varphi_{q s}{ }^{2}} \\
& \mathrm{I}_{\mathrm{dr} \_ \text {ref }}=-\frac{2 \mathrm{~L}_{\mathrm{s}} \mathrm{T}_{\mathrm{e}_{-} \text {ref }}}{3 \mathrm{p} \mathrm{L}_{\mathrm{m}} \varphi_{\mathrm{s}}} \\
& \mathrm{P}_{\mathrm{e}_{-} \text {ref. }}=\mathrm{T}_{\mathrm{e}_{-} \text {ref }} \omega_{\mathrm{m}}=\mathrm{P}_{\mathrm{optimal}}-\mathrm{P}_{\text {loss }} \\
& \mathrm{I}_{\mathrm{qr} \_ \text {ref }}=\mathrm{I}_{\mathrm{ms}}+\frac{2}{3} \frac{\mathrm{Q}_{\mathrm{s}}}{\mathrm{V}_{\mathrm{ds}}} \frac{\mathrm{L}_{\mathrm{s}}}{\mathrm{L}_{\mathrm{m}}}=\frac{\varphi_{\mathrm{s}}}{\mathrm{L}_{\mathrm{m}}}+\frac{2}{3} \frac{\mathrm{Q}_{\mathrm{s}}}{\mathrm{V}_{\mathrm{ds}}} \frac{\mathrm{L}_{\mathrm{s}}}{\mathrm{L}_{\mathrm{m}}}
\end{aligned}
$$

The transfer function (T.F) from $\mathrm{I}_{\mathrm{qr} \_ \text {ref }}$ to $\mathrm{Q}_{\mathrm{s}}$ is given in the following equation and modeled in Figure (5) where $\varphi_{\mathrm{s}} / \mathrm{L}_{\mathrm{m}}$ is neglected [10]

$\mathrm{T} . \mathrm{F}=\frac{\mathrm{Q}_{\mathrm{s}}}{\mathrm{I}_{\mathrm{qr} \_ \text {ref }}}=\frac{3}{2} \frac{\mathrm{V}_{\mathrm{ds} \mathrm{L}_{\mathrm{m}}}}{\mathrm{L}_{\mathrm{s}}}$

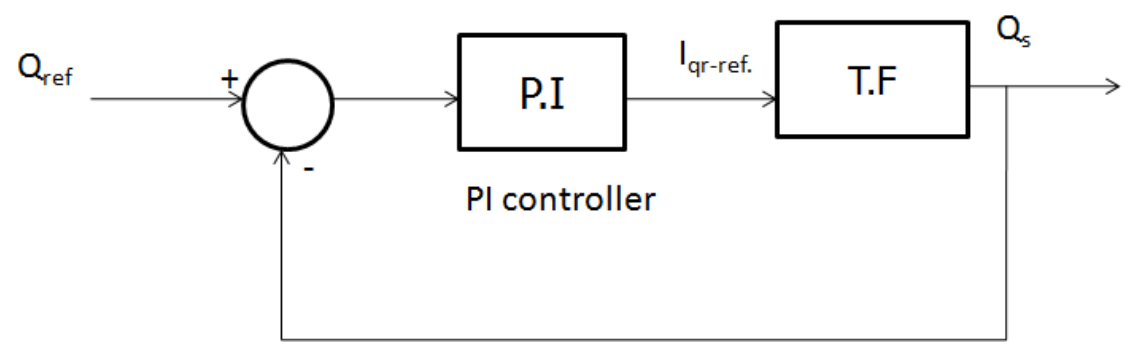

Figure (5) Stator Reactive power control block diagram

In steady-state, the controller should keep the reactive power set equal to zero, therefore maximizing the active power injection to the grid. The RSC in the rotor circuit can be used to control the stator reactive power, exchanged between the stator terminals and the grid, by controlling $\mathrm{I}_{\mathrm{qr} \_ \text {ref }}[10]$.

\section{3-2 Speed Controller}

The simplifications and assumptions used to derive $\mathrm{I}_{\mathrm{dr} \text {-ref }}$ have an impact on the controllability of the torque. The $\mathrm{I}_{\mathrm{dr} \text {-ref }}$ that is fed into the current controller in order to 
achieve the reference torque value is not accurate because it does not take into account the stator resistance. Therefore, the actual torque of the machine will always differ from the reference torque, resulting in a steady-state error. If the mechanical torque $T_{m}$ is set equal to the reference torque $T_{\text {e-ref, }}$ as is common to do, the steady state difference between the two will result in a continuous increase or decrease of the rotor speed due to the swing equation defined in equation (27). This can be corrected with a speed controller in cascade with the current controller that is used to adjust $\mathrm{T}_{\mathrm{e} \text {-ref }}$ in order to keep the rotor speed constant [10].

$\mathrm{T}_{\mathrm{e}}-\mathrm{T}_{\mathrm{L}}=\frac{\mathrm{J}}{\mathrm{p}} \omega_{\mathrm{m}}+\mathrm{B} \omega_{\mathrm{m}}$

The rotor speed reference value can be obtained based on the power-speed relationship of the wind turbine, typically in the form of a table that shows the relationship of rotor speed and the input mechanical power (or mechanical torque). The actual rotor speed can thus be measured and compared to the reference value. The controller gives a reference torque that is fed into the current Controller [10] to satisfy the following equation and shown in Figure (6).

T. F $=\frac{\omega_{\mathrm{m}}}{\mathrm{T}_{\mathrm{e}-\mathrm{ref}}}=1 /\left(\frac{\mathrm{J}}{\mathrm{P}} \mathrm{s}+\mathrm{B}\right)$

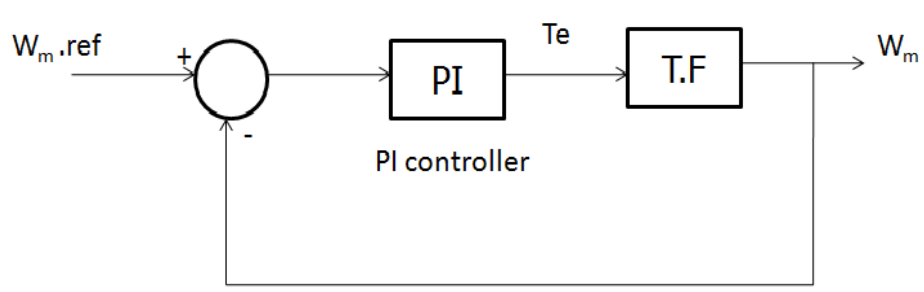

Figure (6) Speed control block diagram

\section{3-3 Design of GSC Controller}

The GSC control scheme also consists of two cascaded control loops. The inner current control loop regulates independently the d-axis and q-axis GSC current components, $I_{d g}$ and $\mathrm{I}_{\mathrm{qg}}$, as shown in

Figure (7). The outer control loop regulates the dc-link voltage and the reactive power exchanged between the GSC and the grid as shown in Figure (8) and Figure (9). In the stator-voltage oriented frame the d-axis of the reference frame is aligned along the statorvoltage space vector. The grid voltage applied to the stator has been assumed to be constant, so the stator q-axis voltage would be zero and the d-axis voltage would be constant i.e. $\mathrm{V}_{\mathrm{s}}=\mathrm{V}_{\mathrm{ds}}, \mathrm{V}_{\mathrm{qs}}=0, \varphi_{\mathrm{s}}=\varphi_{\mathrm{qs}}, \varphi_{\mathrm{ds}}=0$ and the d,q-axes rotor voltage equations can be written as [7, 9].

$\left\{\begin{array}{cl}V_{d g}=V_{d s}-\left(R_{c}+L_{c} p\right) I_{d g}+\omega_{s} L_{c} I_{q g} & =V_{d s}-V_{d g}^{1}+V_{d g}^{2} \\ V_{q g}=V_{q s}-\left(R_{c}+L_{c} p\right) I_{q g}-\omega_{s} L_{c} I_{q g} & =V_{q s}-V_{q g}^{1}-V_{q g}^{2}\end{array}\right.$ 


$$
\begin{aligned}
& \left\{\begin{array}{l}
V_{d g}^{1}=\left(K_{p g}+\frac{K_{i g}}{S}\right)\left(I_{d g-r e f .}-I_{d g}\right) \\
V_{q g}^{1}=\left(K_{p g}+\frac{K_{i g}}{s}\right)\left(I_{q g-r e f .}-I_{q g}\right)
\end{array}\right. \\
& Q_{g}=-\frac{3}{2}\left(V_{d s} I_{q g}\right) \\
& P_{g}=\frac{3}{2}\left(V_{d s} I_{d g}\right) \\
& \text { T.F }=\frac{Q_{g}}{\mathrm{I}_{\text {qg_ref }}}=-(3 / 2) V_{d s}
\end{aligned}
$$
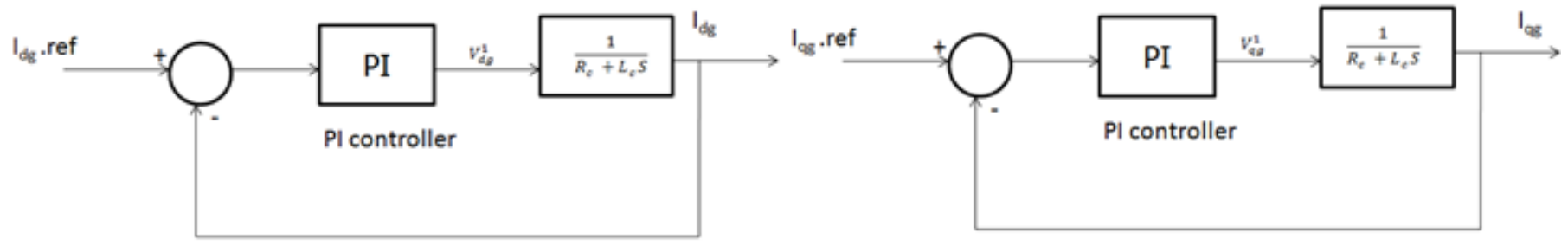

(a) Current regulation part of d-axis GSC voltage

(b) Current regulation part of q-axis GSC voltage

Figure (7) Current regulation parts of GSC voltage

The current reference $\mathrm{I}_{\mathrm{qg} \_ \text {ref }}$ control the reactive power exchanged between the grid and GSC. $I_{d g \_r e f}$ control dc-link voltage $\mathrm{V}_{\mathrm{dc}}$. Generally $\mathrm{I}_{\mathrm{qg} \_ \text {ref }}$ set at zero for zero reactive power output from GSC $[7,10]$. Generating reference currents for GSC can be modeled in Figure (8) and Figure (9)

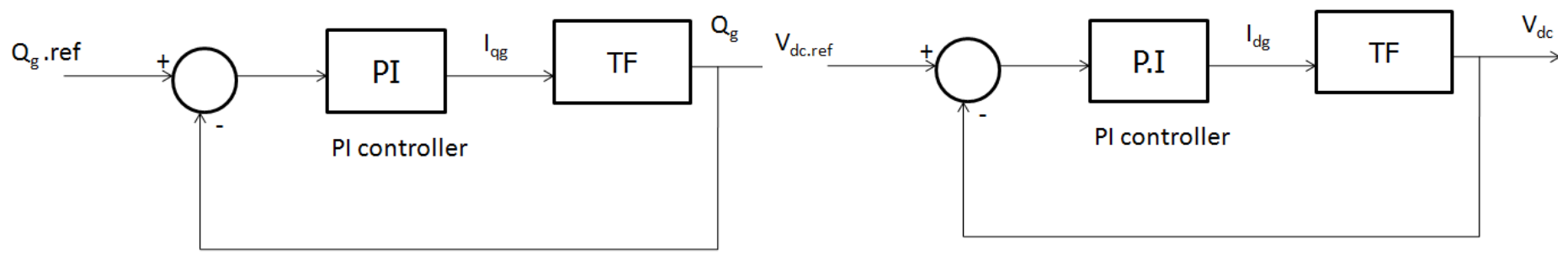

Figure (8) GSC, Reactive power control block diagram
Figure (9) GSC, DC voltage control block diagram

\section{3-4 DC-link Voltage Regulator}

With reference to Figure (1), neglecting the harmonics due to the switching and ignoring the losses in the AC-side resistances and IGBTs, the input power should be equal to the output power, and the following expression can be obtained [5, 9]

$\mathrm{P}_{\mathrm{r}}-\mathrm{P}_{\mathrm{g}}=\mathrm{V}_{\mathrm{dc}} \mathrm{I}_{\mathrm{dc}}=\mathrm{V}_{\mathrm{dc}} \mathrm{C} \mathrm{V}_{\mathrm{dc}}^{\cdot}$ 
$\frac{\mathrm{v}_{\mathrm{dc}}(\mathrm{s})}{\mathrm{P}_{\mathrm{g}}(\mathrm{s})}=\frac{1}{\mathrm{C} V_{\mathrm{dc}} \mathrm{s}}$
$\mathrm{T} . \mathrm{F}=\frac{\mathrm{v}_{\mathrm{dc}}(\mathrm{s})}{\mathrm{I}_{\mathrm{dg}}(\mathrm{s})}=\frac{(3 / 2) \mathrm{V}_{\mathrm{ds}}}{\mathrm{C} \mathrm{v}_{\mathrm{dc}} \mathrm{s}}$

From the previous equations, it can be seen that the DC-link voltage can be controlled by regulating $I_{d g}$ using the transfer function from $P_{g}$ to $V_{d c}$ and the transfer function between $\mathrm{I}_{\mathrm{dg}}$ and $\mathrm{V}_{\mathrm{dc}}$ as listed before.

The difference between the reference and measured values of the DC-link voltage passing through a PI controller and yields the reference value of the d-axis current, as depicted in Figure (9)

$\mathrm{I}_{d g_{-} r e f}=\left(K_{p v}+\frac{K_{i v}}{s}\right)\left(V_{d c-r e f}-V_{d c}\right)$

\section{3-5 Design of The Pitch Angle Controller}

The pitch angle controller is only activated when the wind speed increases above the rated speed. The pitch angle control system will limit the generated power by changing the pitch angle. In such way, the output power will be stabilized at nominal value. The pitch angle control system is depicted in Figure (10) Due to the huge size of blade and the inertia, pitch angle has to change in a slow rate and a reasonable range [3].

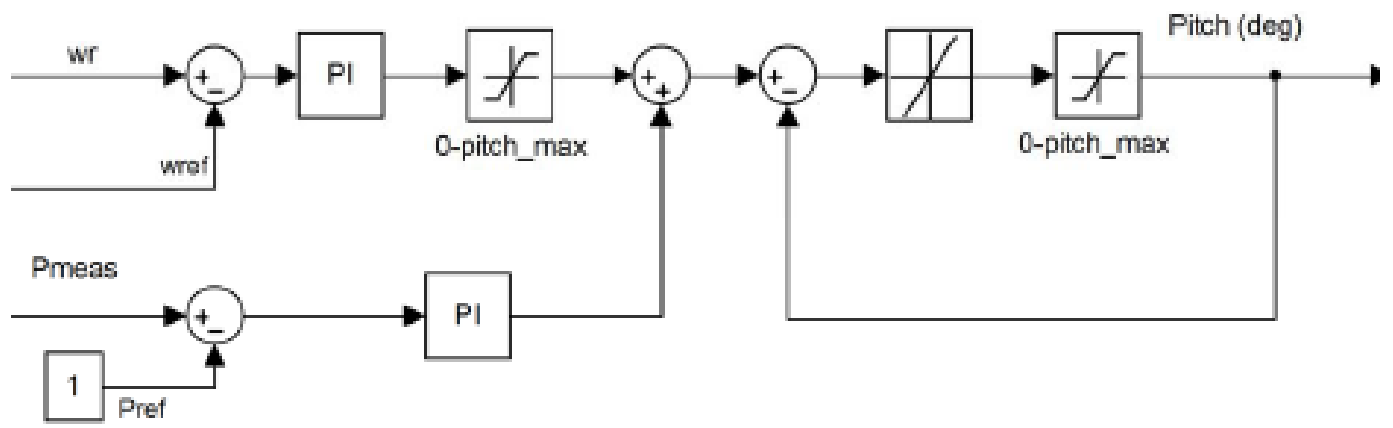

Figure (10) Blade pitch control for wind turbine

All PI controllers have been tuned by Internal Mode Control (I.M.C.) method.

\section{3-6 Internal Mode Control (I.M.C.) Method}

For IMC method, Reaction curve (Step Testing) should be carried out first.

\section{3-6-1 Reaction Curve (Step Testing)}

With the system is in open-loop mode, Step the process input by a small amount $(\Delta \mathrm{u})$ and record the output response till it reaches new steady state as shown in Figure (11). From the obtained response for the output determine the process parameters, gain process $\left(\mathrm{K}_{\mathrm{p}}\right)$, open loop time constant $(\tau)$ and dead time $(\theta)[17]$. 


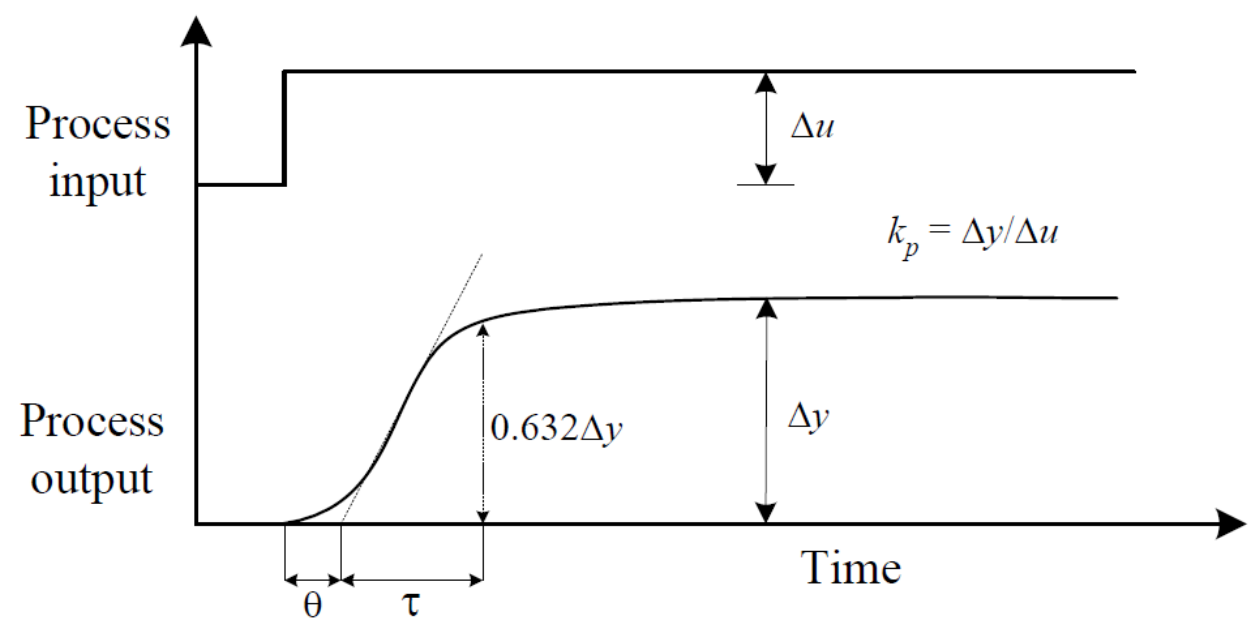

Figure (11) Reaction curve

\section{3-6-2 PI controller tuning by IMC method}

IMC gives a good practices approach to PI controller tuning as in [18]. Tuning is carried out through the following steps:

1-Apply the reaction curve as discussed in 3-6-1 determine process Gain $\left(\mathrm{K}_{\mathrm{p}}\right),(\theta)$ and $(\tau)$.

2-Pick a desired closed loop time constant $\left(\tau_{\mathrm{c}}\right)$ for the control loop .A large value for $\tau_{\mathrm{c}}$ will result in a slow control loop, and a small $\tau_{\mathrm{c}}$ value will result in a faster control loop. Generally, the value for $\tau_{\mathrm{c}}$ should be set as follows[18]:

-Aggressive Tuning: $\tau_{\mathrm{c}}$ is the larger of $0.1 \theta$ or $0.8 \tau$

-Moderate Tuning: $\tau_{\mathrm{c}}$ is the larger of $1.0 \theta$ or $8.0 \tau$

-Conservative Tuning: $\tau_{\mathrm{c}}$ is the larger of $10 \theta$ or $80.0 \tau$

3-Calculate PI controller gains using the equations below[19]:

Controller Gain (Kp)

$\mathrm{Kp}=\frac{\tau}{K_{p}\left(\theta+\tau_{c}\right)}$

Integral gain $(\mathrm{Ki})$

$\mathrm{Ki}=\mathrm{Kp} / \tau$ 


\section{5-Simulation results}

In order to investigate the performance of these control strategies mentioned earlier, a wind turbine-generator system is developed in MATLAB/SIMULINK and simulated under various wind speed conditions. Where the rated wind speed is $13 \mathrm{~m} / \mathrm{s}$. The simulation results for the WECS are given on the next figures.

In this simulation, it has been assumed that the wind speed will vary from $1 \mathrm{~m} / \mathrm{s}$ to $16 \mathrm{~m} / \mathrm{s}$, as shown in Figure (12) to test the system performance.

Figure (13) shows the active power curve. It can be seen that when the wind speed equals $13 \mathrm{~m} / \mathrm{s}$, the power reaches its rated value. When the wind speed increases from $13 \mathrm{~m} / \mathrm{s}$ to $16 \mathrm{~m} / \mathrm{s}$, the active power still equals its rated value. The output active power is regulated by the pitch angle controller. Then, when the wind speed decreases to $13 \mathrm{~m} / \mathrm{s}$, the active power is still kept as its rated value. When the wind speed decreases to $8 \mathrm{~m} / \mathrm{s}$, the output active power also decreases, which is due to the fact that the active power is regulated by the rotor-side converter controller and will track more closely the maximum power.

Since a unity power factor is expected in this system, the reactive power should stay at zero, and from the reactive power curve shown in Figure (14), it can be seen that no matter what the wind speed is, the reactive power keeps its zero value.

The stator direct axis current, shown in Figure (15), has the same active power profile, because of the fact that the active power is directly controlled by the stator direct axis current. So on, the stator quadrature axis current and reactive power which appears on Figure (16).

The electromagnetic torque is controlled by the rotor direct axis current, so they have the same profiles as shown in Figure (17) and Figure (18). One can easily reach this conclusion from equation (23). Figure (19) illustrates that the GSC controller will attempt to keep the DC-link voltage as constant under various wind speed conditions. Figure (20) shows the rotor quadrature axis current profile, which has the same profile of reactive power.

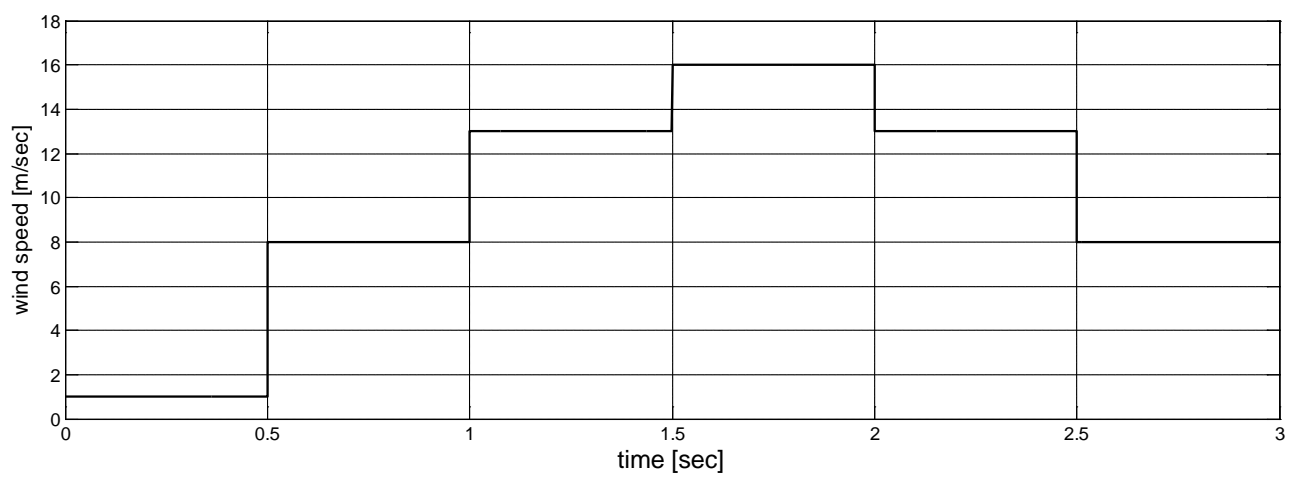

Figure (12) Wind speed profile 


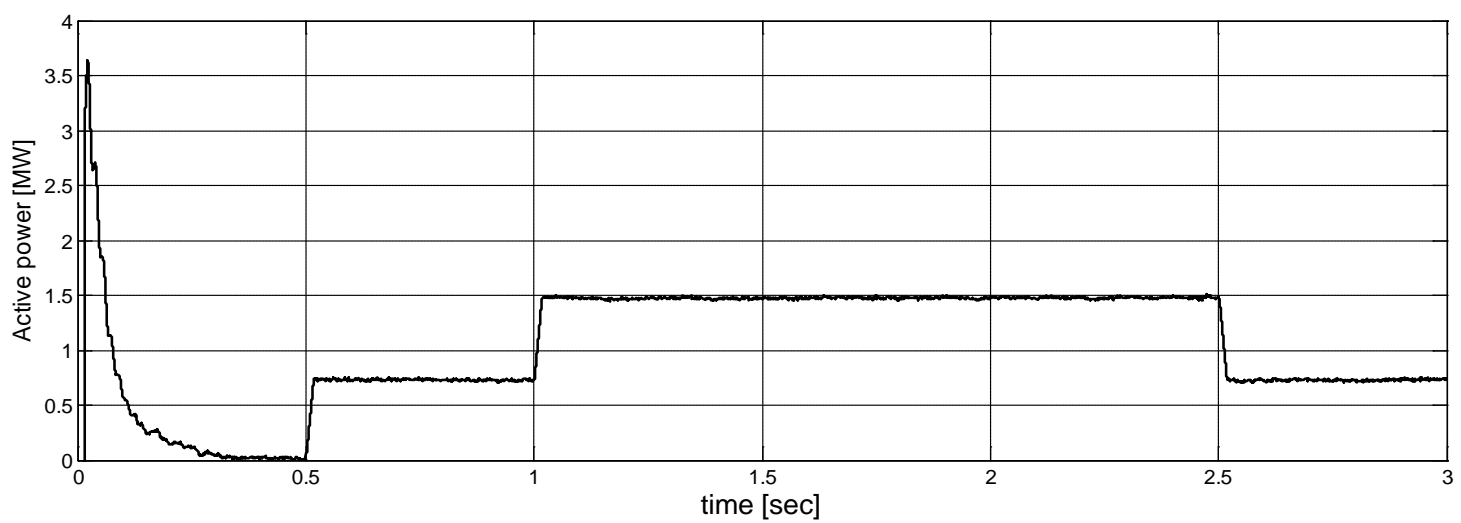

Figure (13) Active power curve

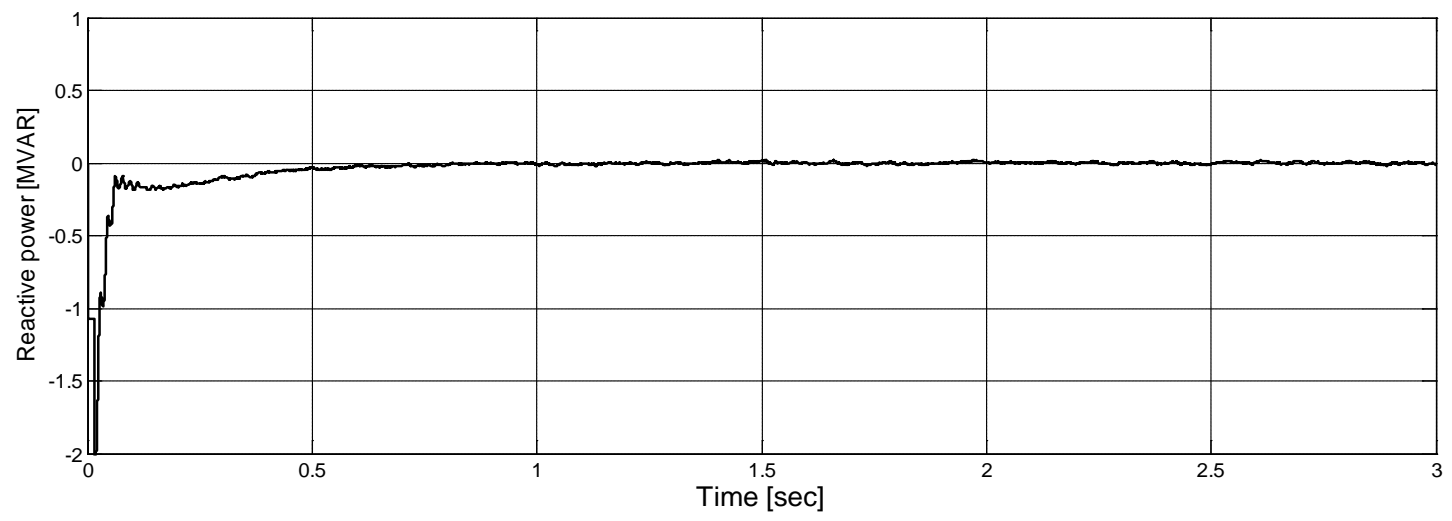

Figure (14) Reactive power curve

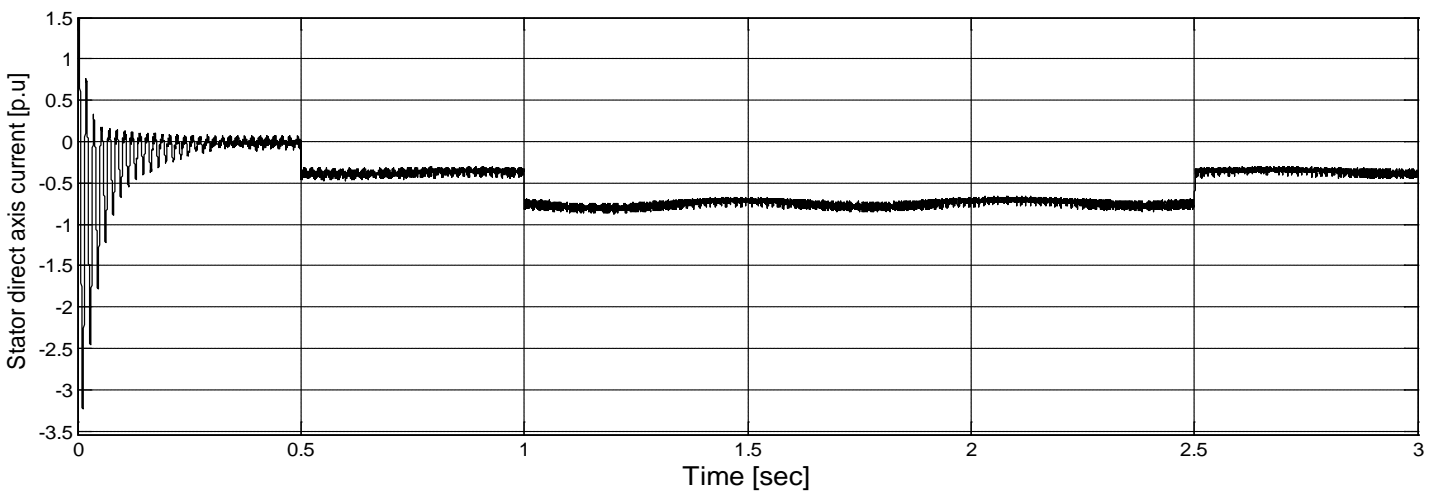

Figure (15) Stator direct axis current profile 


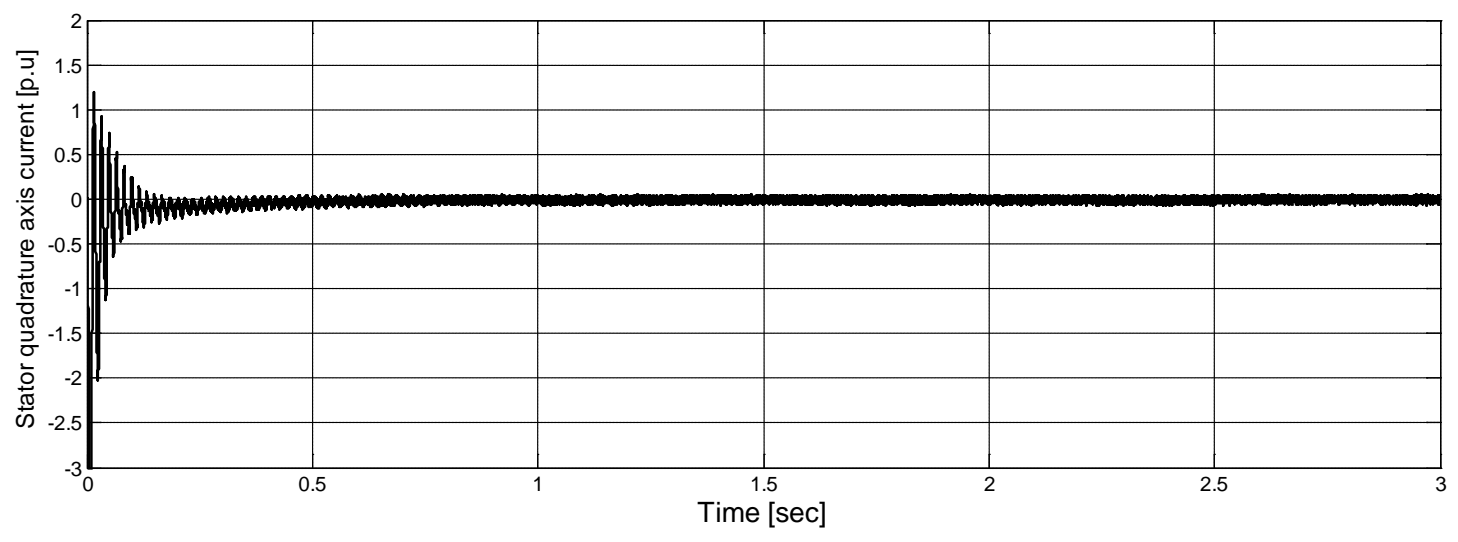

Figure (16) Stator quadrature axis current profile

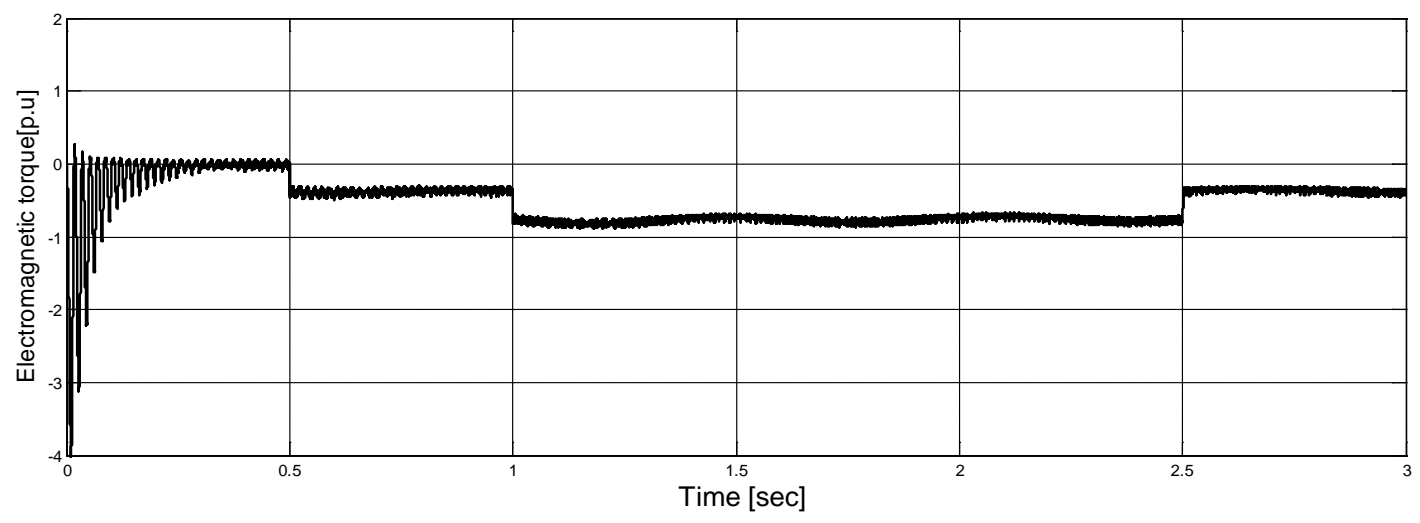

Figure (17) Electromagnetic torque

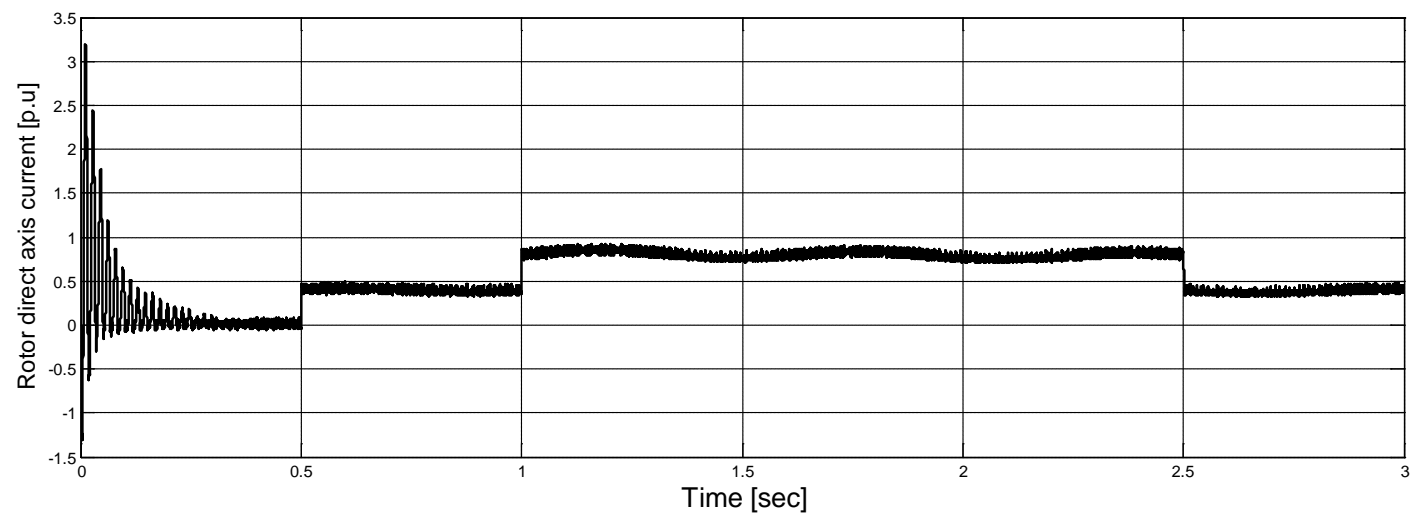

Figure (18) Rotor direct axis current profile 


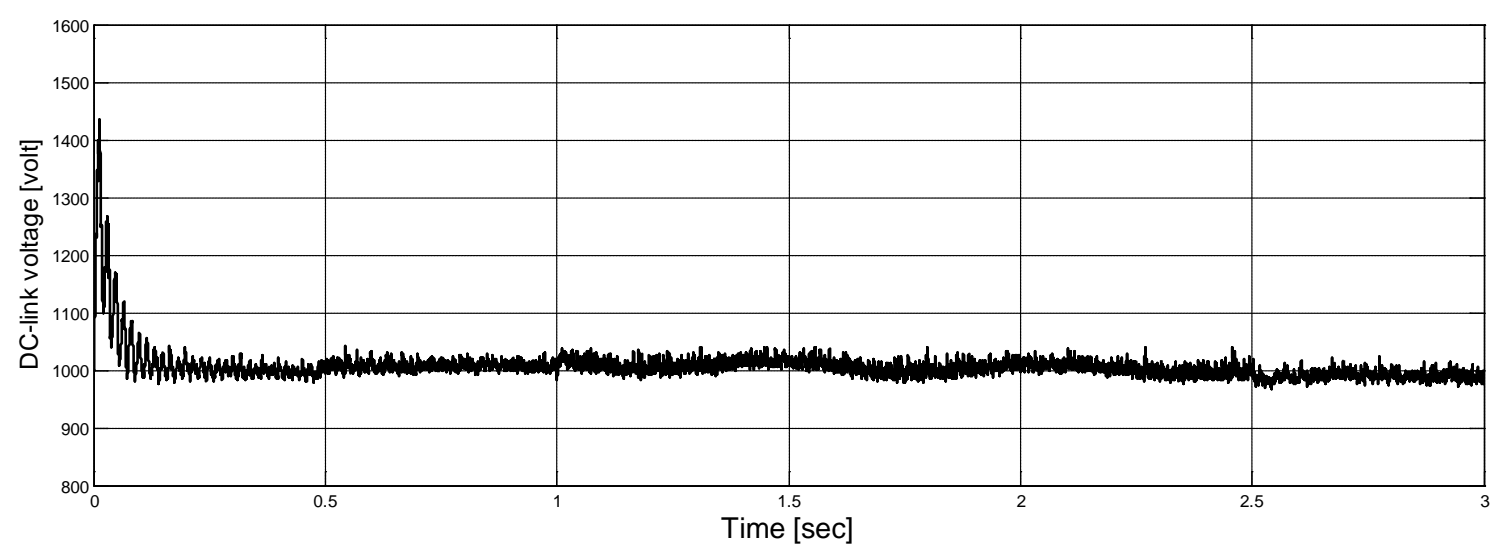

Figure (19) DC-link voltage profile

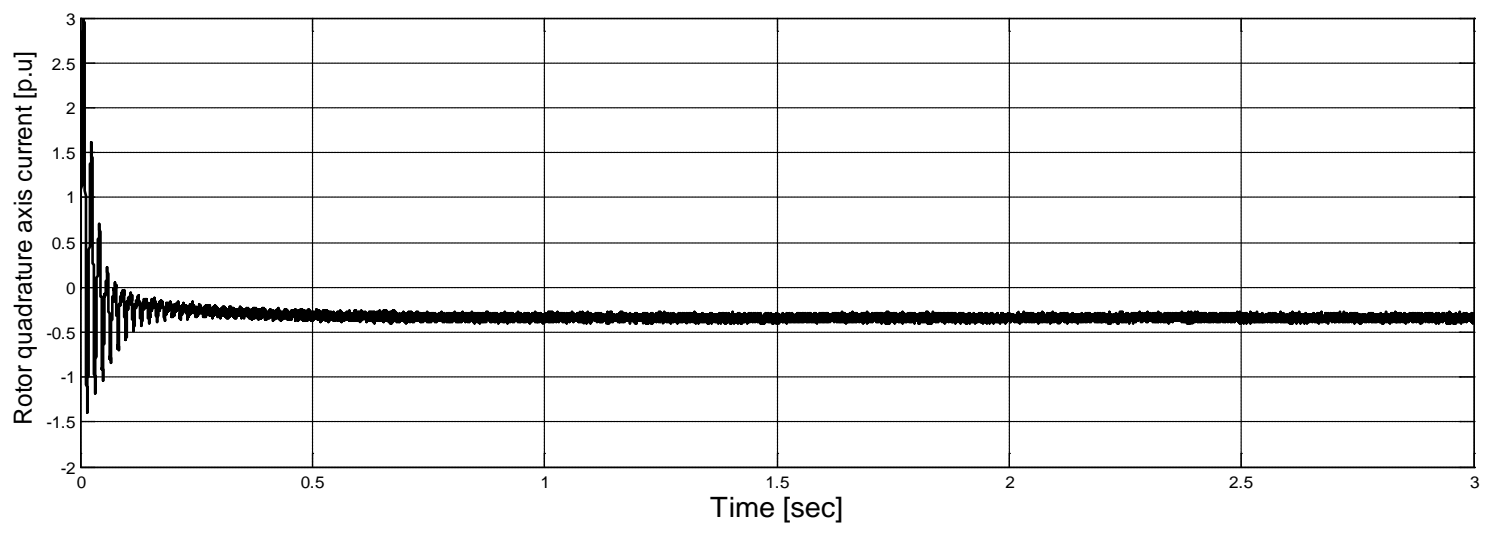

Figure (20) Rotor quadrature axis current profile

\section{5-Conclusion}

In this paper modeling, analysis and control of DFIG and wind turbine have been introduced using MATLAB/SIMULINK. It is found that the mechanical efficiency in a wind turbine is dependent of the power performance coefficient. The power performance coefficient of a rotating wind turbine is given by the pitch angle and tip speed ratio. Adjustable speed improves the system efficiency since the turbine speed can be adjusted as a function of wind speed to maximize output power. Control schemes using standard proportional integral PI controller for variable speed wind turbines, using DFIG are described and simulated for performance prediction. For DFIG a control system considers operating conditions below and above synchronous speed, which are actually achieved by means of a double sided converter joining the machine rotor to the grid. In order to decouple the active and reactive powers generated by the machine, stator-voltage oriented vector control is applied. The wind generator mathematical model developed in this paper is used to show how such a control strategy offers the possibility of controlling the power factor of the energy to be generated. 
Also, control of active and reactive powers is accomplished via RSC through direct and quadrature axes currents. DC-link voltage and reactive power exchanged between GSC and grid are controlled via GSC through direct and quadrature axes currents.

\section{$\underline{\text { nomenclatures }}$}
B damping factor $\left(\mathrm{Kg} \cdot \mathrm{m}^{2} \cdot \mathrm{s}^{-1}\right)$
$\mathrm{C}_{\mathrm{p}} \quad$ power coefficient
C DC- link capacitor
$\mathrm{I}_{\mathrm{ds}} \mathrm{I}_{\mathrm{qs}}$
stator direct and quadrature
currents referred to synchronously
rotating reference frame
$\mathrm{A}_{\mathrm{r}} \quad$ Wind turbine swept area
$\mathrm{v}_{\mathrm{w}}$
Wind speed in $\mathrm{m} / \mathrm{sec}$
$\mathrm{P}_{\mathrm{m}}$
wind turbine Mechanical power
$\mathrm{R}_{\mathrm{s}}, \mathrm{Rr}$
per phase stator and rotor resistances $(\Omega)$
$\mathrm{R}_{\mathrm{c}}$
chock coil Resistance $(\Omega)$
$r$
$\mathrm{I}_{\mathrm{dr}}, \mathrm{I}_{\mathrm{qr}}$
rotor direct and quadrature
currents
$\mathrm{I}_{\mathrm{dg}}, \mathrm{I}_{\mathrm{qg}}$
Grid side converter direct and
quadrature currents referred to synchronously rotating reference frame
$\mathrm{V}_{\mathrm{ds}}, \mathrm{V}_{\mathrm{qs}}$
stator direct and quadrature voltages
$\mathrm{V}_{\mathrm{dr}}, \mathrm{V}_{\text {qr }}$
rotor direct and quadrature voltages
$\mathrm{J} \quad$ moment of inertia of the machine $\left(\mathrm{kg}-\mathrm{m}^{2}\right)$
Te, TL
electromagnetic torque produced by the machine and the load torque from the wind turbine (N.m).
$\mathrm{K}_{\mathrm{pv}}, \mathrm{K}_{\mathrm{iv}} \quad$ Proportional constant and integrator constant link voltage regulator
$\mathrm{K}_{\mathrm{pr}}, \mathrm{K}_{\mathrm{ir}}$
Proportional constant and integrator constant for rotor side converter
$\beta \quad$ blade pitch angle in degrees integrator constant for grid side converter
$\mathrm{K}_{\mathrm{pg}}, \mathrm{K}_{\mathrm{ig}} \quad$ Proportional constant and
$\mathrm{L}_{\mathrm{s}}, \mathrm{L}_{\mathrm{r}}$ per phase stator and rotor self inductance $(\mathrm{H})$
$\mathrm{L}_{\mathrm{m}} \quad$ mutual inductance $(\mathrm{H})$
$\lambda$
tip speed ratio
$\mathrm{L}_{\mathrm{c}} \quad$ chock coil inductance $(\mathrm{H})$
$\varphi_{\mathrm{ds}}, \varphi_{\mathrm{qs}}$
$\varphi_{\mathrm{dr}}, \varphi_{\mathrm{qr}}$
$\omega_{\mathrm{s}}, \omega_{\mathrm{r}}$, $\omega_{\mathrm{m}}, \omega_{\mathrm{w}}$
stator direct and quadrature flux (Wb)
rotor direct and quadrature flux ( $\mathrm{Wb}$ )
synchronous speed, slip speed, rotor speed wind turbine speed (rad/s)
$\mathrm{p}$ number of pole pairs of the machine 


\section{References}

[1] Y. Zou, M. Elbuluk, and Y. Sozer, "Stability analysis of maximum power point tracking (MPPT) method in wind power systems," in Industry Applications Society Annual Meeting (IAS), 2011 IEEE, 2011, pp. 1-8.

[2] A. Perdana, Dynamic models of wind turbines: Chalmers University of Technology, 2008.

[3] M. Elbuluk, Y. Zou, and Y. Sozer, "Simulation Comparisons and Implementation of Induction Generator Wind Power Systems," 2013.

[4] S. Mazari, "Control design and analysis of doubly-fed induction generator in wind power application," The University of Alabama TUSCALOOSA, 2009.

[5] W. Qiao, "Dynamic modeling and control of doubly fed induction generators driven by wind turbines," in Power Systems Conference and Exposition, 2009. PSCE'09. IEEE/PES, 2009, pp. 1-8.

[6] A. M. Kassem, K. M. Hasaneen, and A. M. Yousef, "Dynamic modeling and robust power control of DFIG driven by wind turbine at infinite grid," International Journal of Electrical Power \& Energy Systems, vol. 44, pp. 375-382, 2013.

[7] Y. Zou, "Modeling, control and maximum power point tracking (MPPT) of Doubly-Fed Induction Generator (DFIG) wind power system," THE UNIVERSITY OF AKRON, 2012.

[8] L. H. a. T. T. Andreas Petersson, "Comparison between stator-flux and grid-flux-oriented rotor current con trol of doubly-fed induction," presented at the IEEE, Germany, 2004.

[9] X. Jing, "Modeling and control of a doubly-fed induction generator for wind turbine-generator systems," 2012.

[10] M. A. SNYDER, "Development of Simplified Models of Doubly-Fed Induction Generators (DFIG)," Department of Energy and Environment, CHALMERS UNIVERSITY OF TECHNOLOGY, 2012.

[11] V. C. Ganti, B. Singh, S. K. Aggarwal, and T. C. Kandpal, "DFIG-based wind power conversion with grid power leveling for reduced gusts," Sustainable Energy, IEEE Transactions on, vol. 3, pp. 12-20, 2012.

[12] G. Abad, J. López, M. Rodríguez, L. Marroyo, and G. Iwanski, Doubly fed induction machine: modeling and control for wind energy generation vol. 86: John Wiley \& Sons, 2011.

[13] Y. J. a. J. Back, "Power Regulation of Variable Speed Wind Turbines using Pitch Control based on Disturbance Observer," Journal of Electrical Engineering \& Technology, vol. Vol. 7, No. 2, pp. 273 280, 2012, 2012.

[14] N. W. Miller, W. W. Price, and J. J. Sanchez-Gasca, "Dynamic modeling of GE 1.5 and 3.6 wind turbinegenerators," GE-Power systems energy consulting, 2003.

[15] S. Romphochai and P. Kumkratug, "Modeling and Simulation DFIG Based on Wind Energy Conversion System in MATLAB/SIMULINK," Wind energy, vol. 2, p. 6.

[16] A. Luna, F. d. A. Lima, D. Santos, P. Rodríguez, E. H. Watanabe, and S. Arnaltes, "Simplified modeling of a DFIG for transient studies in wind power applications," Industrial Electronics, IEEE Transactions on, vol. 58, pp. 9-20, 2011.

[17] R. H. Hafez, "Implementing Microprocessor Technology in Aircraft Electrical Power Generation System Control ", MTC,cairo, Egypt, 2013.

[18] R. C. Rice, "ABest-Practices Approach to Understanding and Tuning PID Controllers," PID Tuning Guide For the Allen-Bradley Family of PLCs, 2010.

[19] Jacques.Smuts, "Process Control for Practitioners, How to tune PID controllers and optmize control loops," vol. Book,2011. 